\title{
Impact of Novel Balloon Catheter on Static Balloon Atrial Septostomy With Double Balloon Technique in Infants With Congenital Heart Disease
}

\author{
Hisashi Sugiyama, MD; Kazuto Fujimoto, MD; Tetsuko Ishii, MD; \\ Toshio Nakanishi, MD; Hideshi Tomita, MD
}

\begin{abstract}
Background: The aim of this study was to investigate the feasibility of static balloon atrial septostomy (BAS) with the double balloon technique for infants. TMP PED balloon catheter, newly designed for static BAS in small children, was used in 3 infants. The balloon catheter has a low profile, short and round shoulder, and smooth deflation without slippage.

Methods and Results: Three infants (transposition of the great arteries, $n=2$; pulmonary atresia with intact ventricular septum, $n=1$ ) underwent static BAS with double balloon for restrictive interatrial communication between December 2014 and March 2015. Hemodynamic and echocardiographic assessment was done before and after the procedure. Pressure gradient between left and right atrium decreased from 6,7 and $9 \mathrm{mmHg}$ to $2,2 \mathrm{and} 1 \mathrm{mmHg}$, respectively. Oxygen saturation in systemic artery increased from 72,68 and $73 \%$ to 78,70 and $79 \%$, respectively. Maximum defect diameter increased from $3.5,3.0$ and $3.3 \mathrm{~mm}$ to $6.6 \times 5.2,9.0 \times 6.2$ and $8.1 \times 5.1 \mathrm{~mm}$, respectively. No complication was recorded.
\end{abstract}

Conclusions: Static BAS with double balloon technique using the novel TMP PED balloon catheter was safe and effective in producing sufficient interatrial communication for 8-20 weeks in infants. Static BAS is a promising procedure to create interatrial communication in infants. (Circ $J$ 2015; 79: 2367-2371)

Key Words: Balloon atrial septostomy; Double balloon; Infant

B alloon atrial septostomy (BAS) is the established treatment for neonates with cyanotic congenital heart disease and is still utilized worldwide. ${ }^{1-5}$ Neurological complications related to the procedure, however, are a concern. In addition, patency after the procedure should be considered. ${ }^{6-9}$

The TMP PED balloon catheter (Tokai Medical Products, Aichi, Japan) has been specially designed for static BAS as well as congenital valvular stenosis in infants. We investigated the feasibility of static BAS with the double balloon technique using the TMP PED balloon catheter. Three infants underwent the procedure.

\section{Methods}

The TMP PED balloon catheter is a $65-\mathrm{cm}$-long dual lumen catheter that comes in a 4-mm, 6-mm, 8-mm or $10-\mathrm{mm}$ diameter $\times 20$-mm-long semi-compliant balloon made of polyamide elastomer. It has an end hole that will accommodate a
0.014 -inch guidewire. Rated burst pressure is 4 atm at a balloon diameter of 4, 6 and $8 \mathrm{~mm}$, and $3.5 \mathrm{~atm}$ at a diameter of $10 \mathrm{~mm}$. Minimum sheath size is $3 \mathrm{Fr}$ for all series. The balloon has a short and round shoulder shape, as well as an extremely short tip, to prevent vessel or cardiac wall injury, particularly in lesions with small distal space (Figure 1).

\section{Patients}

Three infants were diagnosed as requiring atrial septostomy for restrictive interatrial communication between December 2014 and March 2015. Patient characteristics are listed in Table 1. Age ranged from 2 to 9 months. Body weight ranged from 3.5 to $6.7 \mathrm{~kg}$ and length of atrial septum, measured on 4-chamber view on echocardiography, ranged from 26 to $28 \mathrm{~mm}$. Patients 1 and 3 had transposition of the great arteries, ventricular septal defect and pulmonary stenosis with severe cyanosis due to restrictive interatrial communication. Patient 2 had pulmonary atresia with intact ventricular septum with symptoms related to right heart failure due to restrictive

Received April 30, 2015; revised manuscript received July 24, 2015; accepted July 26, 2015; released online August 25, 2015 Time for primary review: 33 days

Pediatric Cardiology, Tokyo Women's Medical University, Tokyo (H.S., T.I., T.N.); Cardiovascular Center, Showa University Northern Yokohama Hospital, Yokohama (K.F., H.T.), Japan

Mailing address: Hisashi Sugiyama, MD, Pediatric Cardiology, Tokyo Women's Medical University, 8-1 Kawada, Shinjuku-ku, Tokyo 162-8666, Japan. E-mail: psugiyama@hij.twmu.ac.jp

ISSN-1346-9843 doi:10.1253/circj.CJ-15-0480

All rights are reserved to the Japanese Circulation Society. For permissions, please e-mail: cj@j-circ.or.jp 


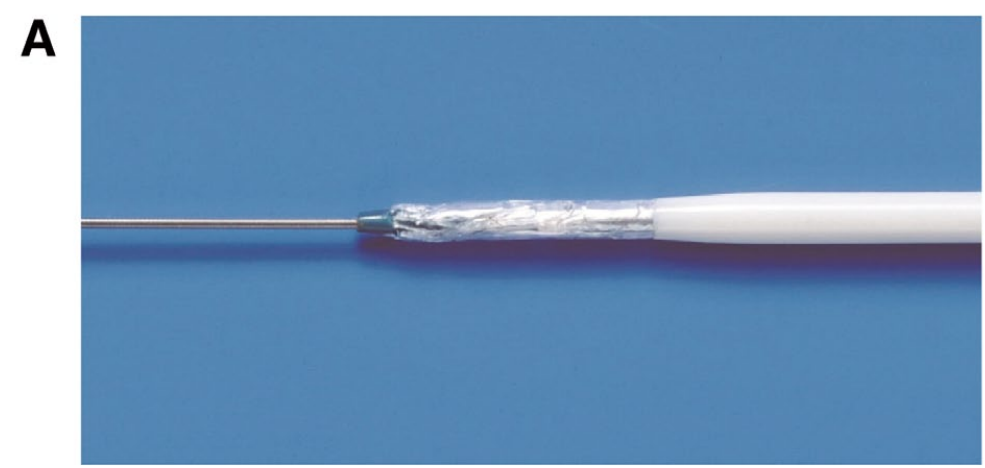

B

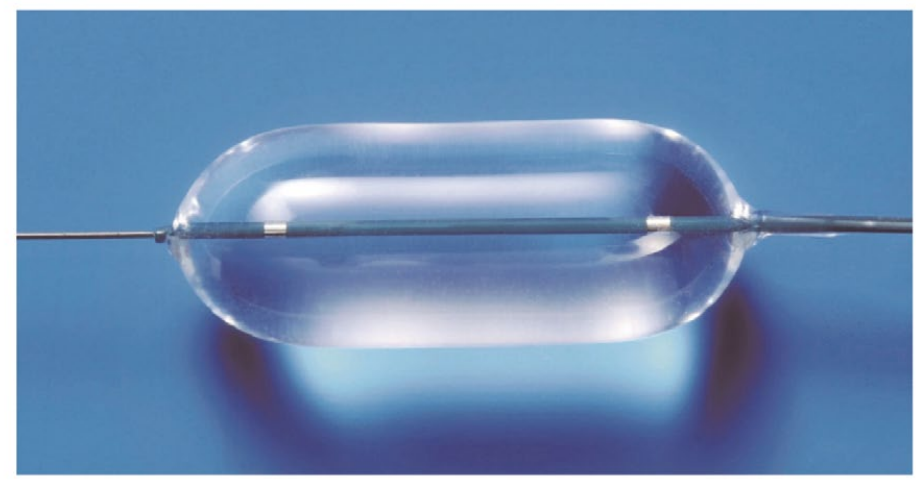

Figure 1. TMP PED balloon catheter: (A) before inflation; (B) inflated.

\begin{tabular}{|lccc|}
\hline Table 1. Patient Characteristics & & & 2 \\
Patient ID no. & $\mathbf{1}$ & 9 & 3 \\
Age (months) & 8 & $6.7 / 66$ & 2 \\
Body weight $(\mathrm{kg}) /$ Body height $(\mathrm{cm})$ & $6.4 / 65$ & PA with IAS & TGA III \\
Diagnosis & Dextrocardia, TGA III & Right mod. BT & Right mod. BT \\
Previous operation & Right mod. BT & 28 & 26 \\
Length of atrial septum $(\mathrm{mm})^{\dagger}$ & 27 & Static BAS TMP-PED & Blade atrial septostomy \\
Previous catheter intervention & Pull back BAS (Rashkind) & $8 \mathrm{~mm}+10 \mathrm{~mm}$ & Static BAS TMP-PED \\
Initial procedure & Static BAS TMP-PED & & $8 \mathrm{~mm}+10 \mathrm{~mm}$ \\
Subsequent procedure & $8 \mathrm{~mm}+10 \mathrm{~mm}$ & & \\
\end{tabular}

†Measured on 4-chamber view. BAS, balloon atrial septostomy; mod. BT, modified Blalock-Taussig shunt; PA with IAS, pulmonary atresia with intact ventricular septum; TGAlll, transposition of the great arteries with ventricular septal defect and pulmonary stenosis.

interatrial communication. All patients had undergone palliative right modified Blalock-Taussig shunt operation during the neonatal period. Only patient 1 previously underwent BAS with the conventional Rashkind method. Before the procedure, written informed consent was obtained from all parents or guardians.

\section{Procedure}

After insertion of a 3-Fr or 4-Fr sheath in the femoral vein, oxygen saturation was measured from superior vena cava and descending aorta. A pressure pull-back was recorded from the left to right atrium. An additional 3-Fr sheath was inserted in the contralateral femoral vein. A multipurpose catheter was placed in the left atrium. A guidewire (0.014 inch; Thruway,
Boston Scientific, Marlborough, MA, USA) was placed and the catheter was exchanged for 10- and 8-mm diameter TMP PED balloon catheters over the guidewire one by one. After adjusting the position of both balloons to straddle the atrial septum, both balloon catheters were simultaneously inflated with diluted contrast medium up to $3.5 \mathrm{~atm}$ (Figure 2). After the procedure, pressure study, oxygen saturation measurement and echocardiography were performed.

\section{Results}

Hemodynamic and echocardiographic parameters are listed in Table 2. Mean pressure gradient between the left atrium and right atrium decreased from 6,7 and $9 \mathrm{mmHg}$ to 2,2 and 
A

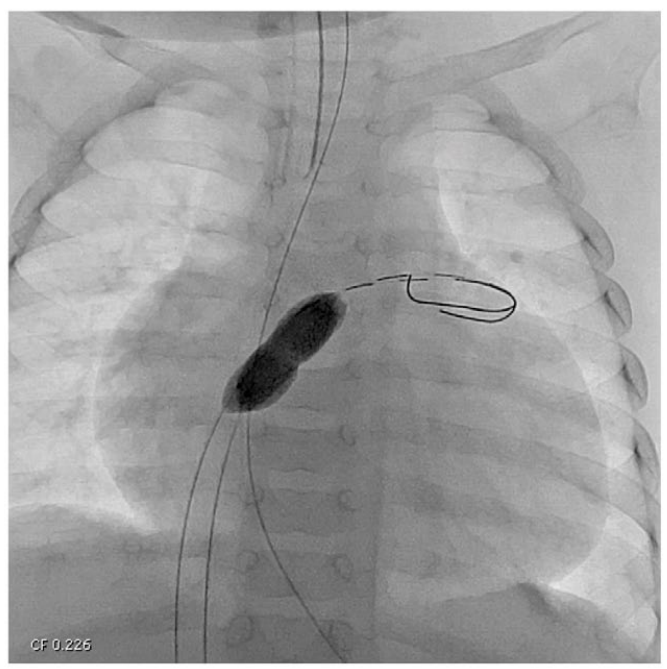

B

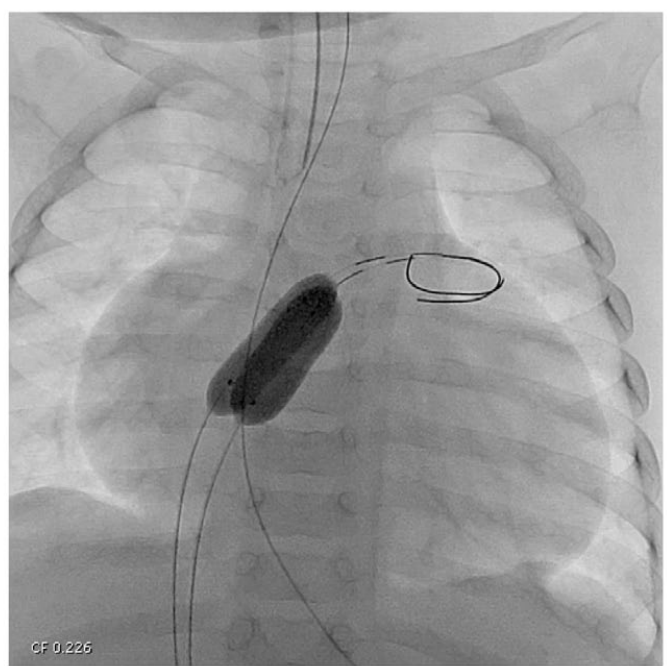

Figure 2. (A) Indentation of the balloon implies atrial septum on fluoroscopy; (B) full inflation of TMP PED balloon catheter.

$1 \mathrm{mmHg}$, respectively. Oxygen saturation in the systemic artery increased from 72,68 and $73 \%$ to 78,70 and $79 \%$, respectively. Maximum defect diameter increased from 3.5, 3.0 and $3.3 \mathrm{~mm}$ to $6.6 \times 5.2,9.0 \times 6.2$ and $8.1 \times 5.1 \mathrm{~mm}$ (Figure 3 ), respectively. Because of thick atrial septum, blade atrial septostomy was performed to make clue of the tear before static BAS in patient 3. Defect size was almost unchanged 5 months after the procedure in patient 1 , and at 2 months after the procedure in patient 3 . In patient 2 , bilateral bidirectional Glenn operation was performed 1 month after static BAS. A $10-\mathrm{mm}$ tear was found at the middle of the atrial septum in patient 2. During the procedure, hemodynamics were stable. No complication was recorded in all 3 children.

\section{Discussion}

Surgical and medical progress could improve clinical outcome in infants with congenital heart disease..$^{10,11}$ Meanwhile, BAS is still regarded as the standard technique for sick infants. It was introduced by Rashkind and Miller in 1966 to provide palliation for transposition of the great arteries, pulmonary atresia with intact ventricular septum and other complex heart diseases. ${ }^{1-3}$ Although the necessity to create an interatrial communication in neonates with "simple" transposition of the great arteries is now reduced with early repair, those infants with pulmonary atresia with intact ventricular septum and hypoplastic left heart syndrome still require creation of longterm interatrial communication. Although transposition of the great arteries with ventricular septal defect and pulmonary stenosis rarely require BAS, long-term patency of interatrial communication may be required in some cases.

Rashkind balloon (Medtronic, Minneapolis, MN, USA) or Miller catheter (Edward-Baxter Healthcare Corporation, Irvine, CA, USA) have been the conventional balloon catheters for pull-back BAS and require 6-Fr or 7-Fr sheaths, respectively. These balloons are made of latex, which has the potential for balloon fragment embolization. Z-5 septostomy

\begin{tabular}{|lccc|}
\hline $\begin{array}{l}\text { Table 2. Change in Parameters After Static BAS With Double } \\
\text { Balloon } \\
\quad \text { Patient ID no. }\end{array}$ & $\mathbf{1}$ & $\mathbf{2}$ & $\mathbf{3}$ \\
$\begin{array}{l}\text { Before intervention } \\
\text { Mean LAP (mmHg) }\end{array}$ & 9 & 10 & 16 \\
Mean RAP (mmHg) & 3 & 17 & 7 \\
Defect size (max. diameter) & 3.5 & 3.0 & 3.3 \\
Maximum velocity (m/s) & 1.1 & 1.8 & 1.2 \\
Oxygen saturation of aorta (\%) & 72 & 68 & 73 \\
After intervention & & & \\
Mean LAP (mmHg) & 8 & 13 & 8 \\
Mean RAP (mmHg) & 6 & 15 & 7 \\
Defect size (max. diameter) & 6.6 & 9.0 & 8.1 \\
Maximum velocity (m/s) & 1.0 & 0.7 & 0.7 \\
Oxygen saturation of aorta (\%) & 78 & 70 & 79 \\
\hline
\end{tabular}

LAP, left atrial pressure; RAP, right atrial pressure. Other abbreviation as in Table 1.

catheter (NuMed, Hopkington, NY, USA) was also introduced for pull-back BAS in 1997. ${ }^{12}$ The balloon catheter is equipped with dual lumen for guidewire. The incidence of complications in pull-back BAS has been reported at $0-11 \%$., $, 5,13$ Potential risks of the method include (1) injury to the inferior vena cava; ${ }^{3}$ (2) embolization with latex balloon fragment after rupture ${ }^{3}$ and (3) thrombosis in the femoral or iliac vein after BAS in neonates with transposition of the great arteries. ${ }^{14}$ Although the relationship between BAS and neurological complications is still controversial, BAS could be associated with multiple risk factors for thrombosis related to the vascular access and to effects of the procedure itself. ${ }^{3-5,7}$ On magnetic resonance imaging, brain injury was more common in neonates with transposition of the great arteries after BAS than in those without BAS. ${ }^{7}$ 
A

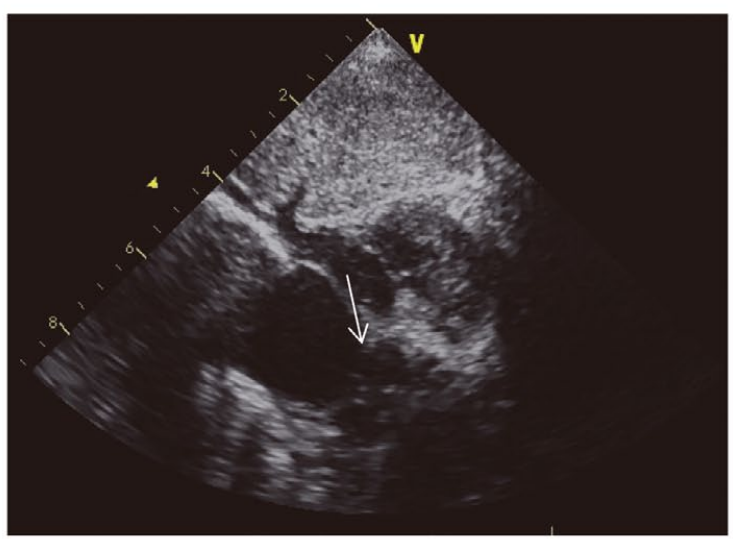

B

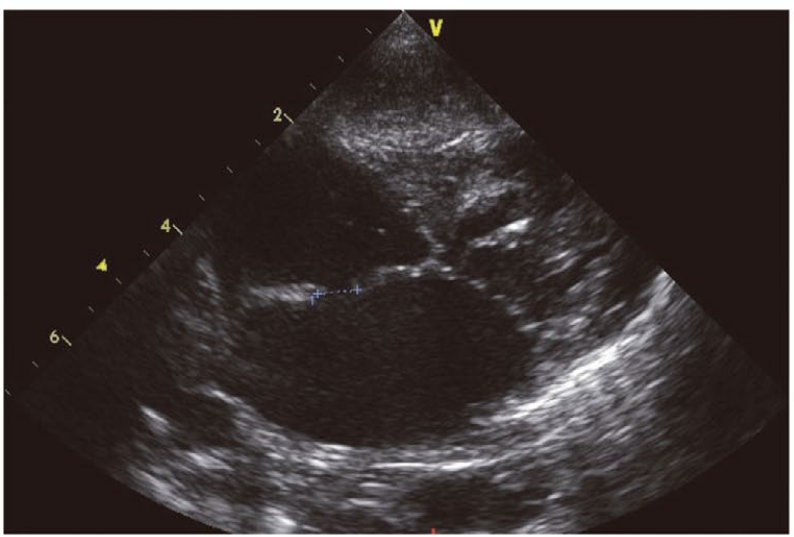

Figure 3. (A) Slit-like interatrial communication before the procedure (white arrow); (B) large interatrial communication after the procedure.

A

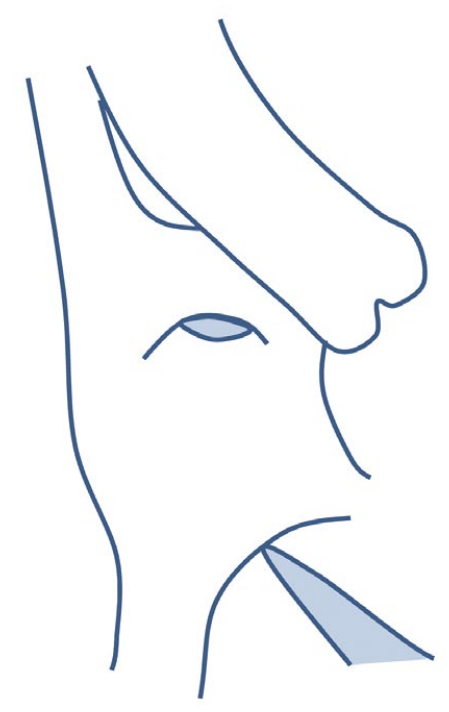

B

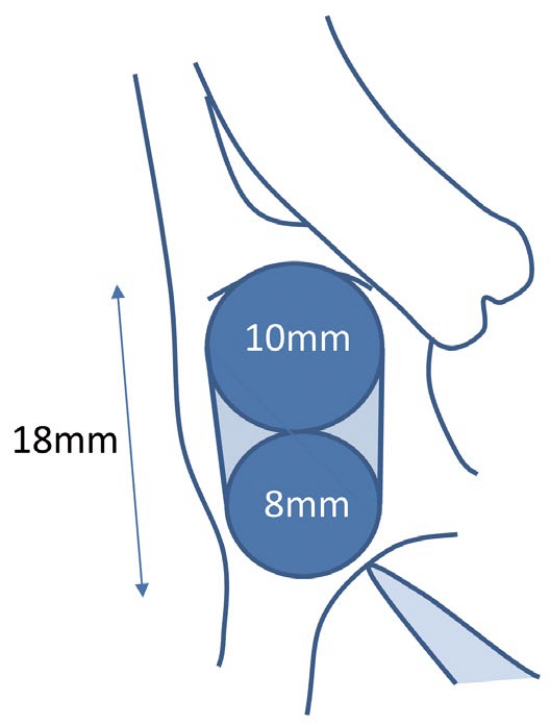

Figure 4. Schematic diagram: (A) slitlike interatrial communication before the procedure; $(\mathbf{B})$ over-stretch of the atrial septum with the double balloon technique.
Static BAS is an alternative method to create interatrial communication. ${ }^{14-18}$ The mechanism of creation of interatrial communication using this procedure is different to that in conventional pull-back BAS. The pull-back technique produces a tear by avulsion, whereas static BAS produces a tear by over-stretching with the balloon in a fixed position. In an experimental study using static BAS, remote embolic lesions in systemic organ were not found and interatrial communications remained patent for 4-14 weeks. In that study, a >15-mm diameter balloon catheter was necessary to produce effective atrial communication. ${ }^{15}$ In general, large balloons have a long shoulder and require a large sheath. Long shoulder or longer balloon length could increase the risk of left appendage rupture, and large sheath in the femoral vein could cause systemic thromboembolism after sheath removal. The double balloon technique can overcome these drawbacks, although it costs twice as much and requires an additional sheath insertion. Issues of the double balloon technique involve instability, given that the balloons can slip easily at inflation. In particular, the low-profile balloon for infants has limited supportability owing to the flexible thin shaft and thin guidewire. Beyond the neonatal period, the atrial septum could thicken. Thus, the Rashkind balloon catheter could not be pulled through the atrial septum in infants. Meanwhile, static BAS could be applied even for thick atrial septum in infants, as in the present series. In patient 3, blade atrial septostomy was performed before static BAS because of thick atrial septum. Necessity of blade atrial septostomy before static BAS should be considered 
according to the thickness of the atrial septum. Static BAS with double balloon technique for neonates is controversial, because the double balloon technique requires an additional sheath insertion, but large and long-lasting atrial communication is not always necessary.

The TMP PED balloon catheter was specially designed for static BAS, as well as valvular stenosis in infants. Balloon size varies from $4 \mathrm{~mm}$ to $10 \mathrm{~mm}$ in $2-\mathrm{mm}$ increments.

The balloon is made of polyamide elastomer, which engages native tissue well without slippage. Diluted contrast medium can simultaneously expand both balloons. Consequently, the double balloon catheter can be inflated without slippage as easily as a single balloon catheter. Furthermore, the ideal short and round shoulder would not injure the vessels and cardiac wall. Although a combination of $10-\mathrm{mm}$ and $8-\mathrm{mm}$ diameter balloons equals the $14.8 \mathrm{~mm}$ diameter of a single balloon, the sum of the balloon diameters is $18 \mathrm{~mm}$, which provides enough over-stretch to create sufficient atrial communication (Figure 4). In the present study, the sum of balloon diameters was shorter than the length of the atrial septum in all patients. Patency of the interatrial communication produced with the double balloon technique was satisfactory in this series. A 10-mm tear, which ran down from the limbus of the foramen ovale, was found at the time of surgery in patient 2 . In the remaining 2 children, follow-up echocardiography showed patent interatrial communication.

\section{Study Limitations}

This study was limited by its retrospective nature and the small number of subjects. Comparison of the present method and the conventional method was not analyzed.

\section{Conclusions}

Static BAS with the double balloon technique using the novel TMP-PED balloon catheter was safe and effective in creating interatrial communication.

\section{Conflict of Interest}

The authors declare no conflicts of interest.

\section{References}

1. Rashkind WJ, Miller WW. Creation of an atrial septal defect without thoracotomy: A palliative approach to complete transposition of the great arteries. JAMA 1966; 196: 991-992.

2. Rashkind WJ, Miller WW. Transposition of the great arteries: Results of palliation by balloon atrioseptostomy in thirty-one infants. Circulation 1968; 38: 453-462.

3. Rashkind WJ. Atrioseptostomy by balloon catheter in congenital heart disease. Radiol Clin North Am 1971; 9: 193-202.

4. Rashkind WJ. Balloon atrioseptostomy revisited: The first fifteen years. Int J Cardiol 1983; 4: 369-378.

5. Venables AW. Balloon atrial septostomy in complete transposition of great arteries in infancy. Br Heart J 1970; 32: 61-65.

6. Doshi H, Venugopal P, MacArthur K. Does a balloon atrial septostomy performed before arterial switch surgery increase adverse neurological outcomes? Interact Cardiovasc Thorac Surg 2012; 15: $141-143$.

7. McQuillen PS, Hamrick SE, Perez MJ, Barkovich AJ, Glidden DV, Karl TR, et al. Balloon atrial septostomy is associated with preoperative stroke in neonates with transposition of the great arteries. Circulation 2006; 113: 280-285.

8. Applegate SE, Lim DS. Incidence of stroke in patients with d-transposition of the great arteries that undergo balloon atrial septostomy in the University Healthsystem Consortium Clinical Data Base/ Resource Manager. Cathet Cardiovasc Intervent 2010; 76: 129-131.

9. Mukherjee D, Lindsay M, Zhang Y, Lardaro T, Osen H, Chang DC, et al. Analysis of 8681 neonates with transposition of the great arteries: Outcomes with and without Rashkind balloon atrial septostomy. Cardiol Young 2010; 20: 373-380.

10. Chen JW, Chen YS, Chang CI, Chiu IS, Chou NK, Huang HH, et al. Risk stratification and outcome of cardiac surgery for patients with body weight $<2,500 \mathrm{~g}$ in an Asian center. Circ J 2014; 78: 393-398.

11. JCS Joint Working Group. Guidelines for drug therapy in pediatric patients with cardiovascular diseases (JCS 2012): Digest version. Circ J 2014; 78: 507-533.

12. Hijazi ZM, Abu Ata I, Kuhn MA, Cheatham JP, Latson L, Geggel RL. Balloon atrial septostomy using a new low-profile balloon catheter: Initial clinical results. Cathet Cardiovasc Diagn 1997; 40: $187-190$.

13. Neches WH, Mullins CE, McNamara DG. Balloon atrial septostomy in congenital heart disease in infancy. Am J Dis Child 1973; 125: $371-375$.

14. Mathews RA, Park SC, Neches WH, Fricker FJ, Lenox CC, Zuberbuhler JR. Iliac venous thrombosis in infants and children after cardiac catheterization. Cathet Cardiovasc Diagn 1979; 5: 67-74.

15. Mitchell SE, Anderson JH, Swindle MM, Strandberg JD, Kan J. Atrial septostomy: Stationary angioplasty balloon technique-experimental work and preliminary clinical applications. Pediatr Cardiol 1994; 15: 1-7.

16. Tomita H, Hatakeyama K, Soda W, Watanabe M, Takagi N. Static balloon atrial septostomy with buddy wire technique: A case report. J Cardiol 2007; 50: 259-262.

17. Ballerini L, di Carlo DC, Cifarelli A, Onorato E, Vairo U. Oversize balloon atrial septal dilatation: Early experience. Am Heart J 1993; 125: $1760-1763$.

18. Shrivastava S, Radhakrishnan S, Dev V, Singh LS, Rajani M. Balloon dilatation of atrial septum in complete transposition of great artery: A new technique. Indian Heart J 1987; 39: 298-300. 